\title{
Abstract
}

\section{Pattern of atherosclerotic coronary artery stenosis among the patients with coronary artery ectasia}

Bandara HGWAPL ${ }^{1}$, Kodithuwakku NW ${ }^{1}$, Kogulan $\mathrm{T}^{1}$, Jegavanthan $\mathrm{A}^{1}$, Hewarathna UI ${ }^{1}$, Siribaddana $\mathrm{MAH}^{1}$, Ambagammana DMJMH ${ }^{1}$, Weerakoon WMG ${ }^{1}$

${ }^{1}$ Cardiology Unit, Teaching Hospital, Kandy, Sri Lanka

\section{Key words: Cardiology, Coronary artery ectasia, Acute coronary symdrome, Coronary} angiography, Coronary artery atherosclerosis

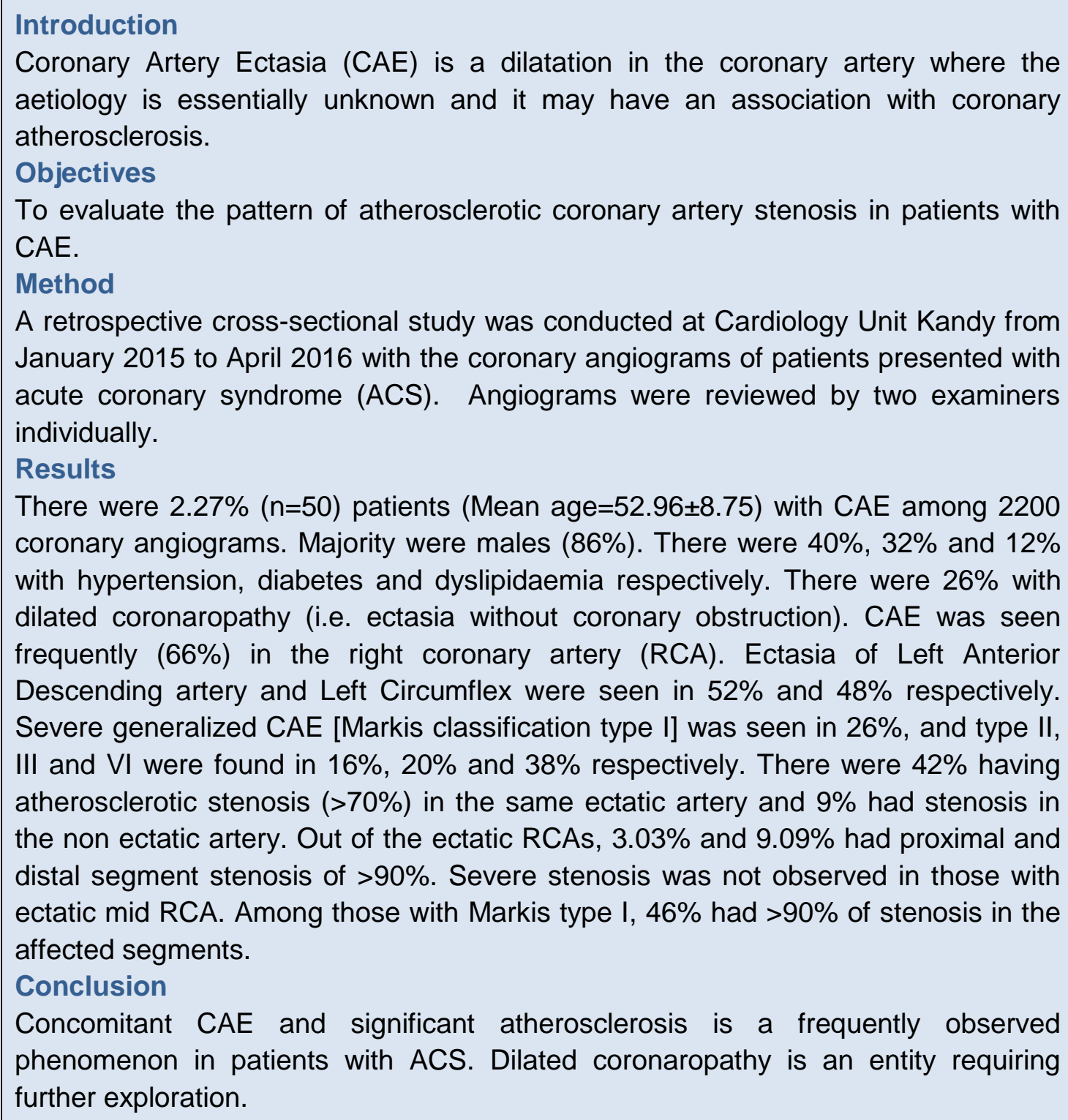

To evaluate the pattern of atherosclerotic coronary artery stenosis in patients with CAE.

Method

A retrospective cross-sectional study was conducted at Cardiology Unit Kandy from January 2015 to April 2016 with the coronary angiograms of patients presented with acute coronary syndrome (ACS). Angiograms were reviewed by two examiners individually.

\section{Results}

There were $2.27 \%(n=50)$ patients (Mean age $=52.96 \pm 8.75)$ with CAE among 2200 coronary angiograms. Majority were males (86\%). There were $40 \%, 32 \%$ and $12 \%$ with hypertension, diabetes and dyslipidaemia respectively. There were $26 \%$ with dilated coronaropathy (i.e. ectasia without coronary obstruction). CAE was seen frequently $(66 \%)$ in the right coronary artery (RCA). Ectasia of Left Anterior Descending artery and Left Circumflex were seen in $52 \%$ and $48 \%$ respectively. Severe generalized CAE [Markis classification type I] was seen in $26 \%$, and type II, III and VI were found in 16\%, 20\% and 38\% respectively. There were $42 \%$ having atherosclerotic stenosis ( $>70 \%$ ) in the same ectatic artery and $9 \%$ had stenosis in the non ectatic artery. Out of the ectatic RCAs, $3.03 \%$ and $9.09 \%$ had proximal and distal segment stenosis of $>90 \%$. Severe stenosis was not observed in those with ectatic mid RCA. Among those with Markis type I, $46 \%$ had $>90 \%$ of stenosis in the affected segments.

\section{Conclusion}

Concomitant CAE and significant atherosclerosis is a frequently observed phenomenon in patients with ACS. Dilated coronaropathy is an entity requiring further exploration.

Corresponding Author: Lakshman Bandara, Email:<lakshmanbandara@gmail.com>

Presentation at the $5^{\text {th }}$ biennial academic sessions of the Postgraduate institute of Medicine on 06 October 2016

Competing Interests: Authors have declared that no competing interests exist. 